\title{
Steroid and Antioxidant in the Treatment of Oral Sub Mucous Fibrosis - A Comparative Study
}

\author{
Abhay D. Havle ${ }^{1}$, Lakshmi Sravya Yarlagadda², Sanket Chandrashekar Prabhune ${ }^{3}$ \\ 1, 2, 3 Department of Otorhinolaryngology, Krishna Institute of Medical Sciences, \\ Deemed to Be University, Karad, Maharashtra, India.
}

\section{ABSTRACT}

\section{BACKGROUND}

Oral Sub Mucous Fibrosis (OSMF) is a common condition found in India due to unique habit of chewing areca nut mixed with pan masala, gutkha, tobacco and spicy food etc. Once started and if neglected it can get transformed into malignancy. The disease once stared can only be controlled with life style changes. We wanted to study the effectiveness of intralesional injection of triamcinolone acetonide, oral llycopene alone and a combination of both in the treatment of oral submucous fibrosis.

\section{METHODS}

This is a randomised comparative study. All cases with history of chewing of areca nut, pan masala, gutkha, tobacco and associated intolerance to spicy food, restricted mouth opening (grade III) and of age ranging between 15 - 70 years irrespective of gender were included in this study. Patients with previous history of treatment for oral sub mucus fibrosis, disorders of temporomandibular joint and pre-malignant conditions such as leukoplakia, drug allergy were excluded. A total of 150 enrolled cases were randomized into group I, II and III and treated with $1 \mathrm{~mL}$ of intralesional injection of triamcinolone acetonide weekly, lycopene capsule twice daily and both in combination respectively for a period of two months. Group II and III cases received oral lycopene throughout the study period, whereas group I and III cases received weekly injection of triamcinolone acetonide till mouth opening of $36 \mathrm{~mm}$ or more was achieved. All cases were followed up every two weeks for entire study period of two months, final follow up after two months and oral cavity was assessed for mucosal ulcerations, palpable fibrous bands, mouth opening in millimetres, and tolerance to spicy foods.

\section{RESULTS}

The number of males and females amongst all groups was 71 and 79 respectively. The most common age group was 51 - 70 years. The mouth opening in 150 cases (grade III) of all groups showed significant improvement $(p<0.001)$ to grades I and II, of which the group III had maximum mouth opening of $20.22 \pm 0.07 \mathrm{~mm}$. Amongst all groups in 143 cases, painful mucosal ulcerations disappeared in 136 (95.10 \%) and majority (49) were from group II. Similarly, amongst all groups in 142 cases the symptom of burning sensation disappeared in 130 (91.5\%), and majority (49) were from group III. Also, amongst all groups in 150, palpable fibrous bands in oral cavity disappeared significantly in $138(92 \%)(p<0.15)$, and the majority (49) were from group III, in remaining 12 it became supple.

\section{CONCLUSIONS}

Group III agent lycopene in combination with triamcinolone acetonide was more effective than triamcinolone acetonide and lycopene of group I and II respectively when used singly in improving the symptoms and signs of OSMF.

\section{KEY WORDS}

Antioxidants, Areca Nuts, Fibrosis, Lycopene, Tobacco, Triamcinolone Acetonide
Corresponding Author: Dr. Lakshmi Sravya Yarlagadda, Resident, Department of Otorhinolaryngology, Krishna Institute of Medical Sciences Deemed to be University, Karad-415110, Maharashtra, India.

E-mail: entpubkimsu@gmail.com

DOI: $10.14260 / \mathrm{jemds} / 2020 / 645$

How to Cite This Article:

Havle AD, Yarlagadda LS, Prabhune SC. Steroid and antioxidant in treatment of oral sub mucous fibrosis- a comparative study. $J$ Evolution Med Dent Sci 2020;9(40):29422946, DOI: $10.14260 /$ jemds/2020/645

Submission 21-07-2020,

Peer Review 28-08-2020,

Acceptance 05-09-2020,

Published 05-10-2020.

Copyright (c) 2020 Abhay D. Havle, et al. This is an open access article distributed under Creative Commons Attribution License [Attribution 4.0 International (CC BY 4.0)] 


\section{BACKGROUND}

Oral Sub Mucous Fibrosis (OSMF) is a chronic insidious, premalignant condition common in India since early 1950 affecting any part of the oral cavity and at times the pharynx and occasionally preceded by and / or associated with vesicle formation. It is always associated with juxta-epithelial inflammation followed by fibro-elastic change of the lamina propria, with epithelial atrophy leading to stiffness of the oral mucosa, trismus and difficulty in eating. ${ }^{1}$

The OSMF has a multifactorial aetiology and exact etiopathogenesis of it is not yet understood. ${ }^{2}$ Several factors such as nutritional deficiency states, areca nut chewing, and genetic susceptibility, and autoimmunity as well as collagen disorders have been postulated to be the possible aetiologies. The most commonly involved site is buccal mucosa, followed by palate, retro molar region, faucial pillars and pharynx and in some cases can even involve the pharynx, larynx, or the oesophagus. ${ }^{3}$ In this condition there is deposition of dense fibrous tissue in the sub-mucous layer of the palate and the cheek leading to disabling sequelae of trismus without any other manifestations in the body.

The disease progresses in three stages-

1. Stage of stomatitis and vesiculation: the mucous membrane appears reddish and may involve the soft palate, anterior pillars or buccal mucous membrane. Clear vesicles appear in these areas which are painful to touch. They may rupture discharging clear fluid leaving behind small superficial ulcers.

2. Stage of fibrosis: the mucous membrane appears pale and spider like stellar bodies appear due to the deposit of fibrous tissue in the sub mucous layer. This fibrosis sets in sub mucosa of palate, uvula, faucial pillars and cheek.

3. Stage of cicatricial contraction and sequelae:

- Palatal: The fibrous tissue increases and the palate may assume whitish discoloration underneath the intact shining mucosa. The normal excursions of the soft palate are restricted.

- Faucial: The fibrous tissue in these areas cause limitation of movements. The palatine tonsils may be crushed, compressed between the fibrous tissue. It may involve pterygomandibular raphe and even pterygoid muscles leading to trismus and inability to open mouth.

- Buccal: Mastication of food becomes difficult due to fibrous infiltration of cheeks. ${ }^{4}$

The disease has a variety of presentations ranging from, excessive salivation, burning sensation, lacking gustatory sensation and limitation of mouth opening leading to difficulty in chewing, swallowing, articulation and poor oral hygiene and its complications.

Lycopene is an antioxidant available in variety of vegetables (tomatoes). It is useful intermediate in the biosynthesis of many carotenoids. Lycopene has anticarcinogenic antioxidant properties and plays important role in treatment of precancerous lesions. Several studies have suggested inhibition of hepatic fibrosis in rats as well as human fibroblast activity in vitro by lycopene, therefore it appears to be a promising agent in the management of OSMF. ${ }^{5}$
Intralesional injection of corticosteroid is being implemented as the first line therapy for patients with mouth opening less than $20 \mathrm{~mm}$. The corticosteroid primarily plays a role of immune modulation besides suppressing the inflammation, decelerating fibrosis and up regulating immune mediated fibrinolytic pathways. ${ }^{6-9}$ So far, studies about use of lycopene in management of OSMF are very few. Therefore, it was a felt need to evaluate and correlate the usefulness of each of lycopene and triamcinolone acetonide injection in isolation and combination while managing OSMF.

\section{METHODS}

This is a randomised comparative study conducted in a tertiary care teaching hospital after ethical clearance from the Institutional Ethics Committee vide letter number KIMSDU / IEC / 04 / 2019 dated 24.07.2019 and a written informed consent. All participants willing to participate in the study, with history of chewing areca nut, pan masala, gutkha, tobacco and associated intolerance to spicy food, restricted mouth opening of grade III and of age between $15-70$ years irrespective of gender were included in this study. Patients with previous history of treatment for oral sub mucus fibrosis, drug allergy, disorders of temporomandibular joint and premalignant conditions such as leukoplakia were excluded. Due to short study period a total of 100 cases were planed initially, and 50 were added later on considering the loss of cases during follow up. All 150 participants fulfilling the inclusion criterions were enrolled and randomized into group I, II and III using lottery method and treated with intralesional injection of triamcinolone acetonide, oral lycopene and combination of both respectively. All cases were subjected to clinical evaluation and diagnosis of OSMF. The status of the progression of disease pathology was graded as per National Journal of Maxillofacial Surgery into 5 grades (Table 1). ${ }^{10}$

\begin{tabular}{|cc|}
\hline Grade I & Maximum interincisal mouth opening up to or $>35 \mathrm{~mm}$. \\
Grade II & Maximum interincisal mouth opening between 25 and $35 \mathrm{~mm}$ \\
Grade III & Maximum interincisal mouth opening between 15 and $25 \mathrm{~mm}$ \\
Grade IV & Maximum interincisal mouth opening 5 and $15 \mathrm{~mm}$ \\
Grade V & Maximum interincisal mouth opening $<5 \mathrm{~mm}$ \\
\hline & Table 1. Grades of Mouth Opening \\
\hline
\end{tabular}

Apart from blood pressure, random blood sugar, complete blood picture, erythrocyte sedimentation rate and haemoglobin to rule out anaemia, brush biopsy was obtained from all cases with ulcerative lesion in mouth and or oropharynx. The option of brush biopsy was resorted to eliminate possibility of excessive fibrosis and resultant increase in restricted mouth opening. Every patient was educated about the nature of the pathology as well as its premalignant potential, and was instructed to discontinue the further use of predisposing abusive habits. Dental opinion was sought for improvement of oral hygiene and prophylaxis. The group-I cases were treated with injection Triamcinolone acetonide (Kenacort $40 \mathrm{mg}$ per $\mathrm{mL}$ ) twice weekly intralesionally at palpable fibrous bands till improvement in mouth opening to $36 \mathrm{~mm}$ or more was achieved. The group-II cases were treated with capsule Lycopene (Lyconex soft gels 5 $\mathrm{mg}$ ) twice daily for two months. The group-III cases were treated with both intralesional injections of Triamcinolone acetonide (Kenacort - $1 \mathrm{~mL}$ containing $40 \mathrm{mg}$ ) improvement in 
mouth opening of $36 \mathrm{~mm}$ or more was achieved and $5 \mathrm{mg}$ of Lycopene twice daily for two months. All cases were followed up fortnightly for 2 months and finally at 2 months after completion of the treatment. At follow up the assessment of oral cavity was carried out to note intolerance to spicy foods and mucosal ulcerations or palpable fibrous bands if any and various grades of mouth opening in every case. The mouth opening was determined by placing the compass between upper and lower incisor teeth and measure tape in millimetres. The refractory cases during follow up were further advised option of surgical modality of treatment for improvement of mouth opening.

Based on the patient's response of sensation of burning in mouth and or oropharynx on presentation and thereafter at biweekly follow up, whether burning sensation was present or absent. Confirmation of the palpable fibrous bands was made by Ultrasonography of buccal mucosa after digital palpation.

\section{Statistical Analysis}

One way ANOVA test was used to compare mouth openings at different time intervals during follow up of cases of all three groups. Paired t test was done to compare between the mouth opening before and after treatment of each of the groups. Chi square test for association between before and after treatment was used in all three groups to compare genders, status of intolerance to spicy food, painful ulceration and palpable fibrous bands.

\section{RESULTS}

Amongst 150 cases of oral sub mucous fibrosis in group I, II and III, there were 71 males and 79 females. After randomization of cases, total number of male and female in group I, II and III was 27 and 23, 19 and 31, 25 and 25 respectively. Statistically there was no significant difference in terms of gender between the groups $(p=0.25)$. The mean age was almost similar in group I, II and III namely $46.52 \pm 15.67$, $43.86 \pm 16.53$ and $47.76 \pm 16.26$ respectively $(p=0.76)$. All cases were between 16 and 69 years of age and majority belonged to 51 - 70 years (Table 2). The mean pre-treatment mouth opening in group I, II and III was $15.93 \pm 3.17,16.21 \pm$ 2.49 and $16.91 \pm 3.56 \mathrm{~mm}$ respectively which improved progressively at $3^{\text {rd }}$ and $7^{\text {th }}$ week as well as at 2 months follow up in all cases. However, the improvement was significant on Tukey-Krammer multiple comparison test only in group III compared to group I at first follow up after 3 weeks $(\mathrm{p}<0.05)$. After improvement post treatment at the end of 2 months the total mouth opening was $32.57 \pm 3.55,32.0 \pm 4.16$ and $37.13 \pm$ $3.49 \mathrm{~mm}$ in all groups respectively with $\mathrm{p}<0.001$ (Table 3 ).

The number of cases having painful mucosal ulcerations prior to treatment was 47, 50 and 46 cases of group I, II and III respectively. After treatment in these cases the pain disappeared following healing of the ulcers in 43,49 and 44 cases respectively. Post treatment out of 143 cases in 136 $(95.10 \%)$ the symptom due to painful mucosal ulcer disappeared (Table 4, 5).

The number of cases havingburning sensation in mouth prior to treatment was 45,48 and 49 cases of group I, II and III respectively. After treatment the disappearance of this symptom noted was in 39, 42 and 49 cases respectively. Post treatment out of 142 cases, 130 (91.5\%) cases became symptom free (Table 4,5).

The presence of palpable fibrous bands in oral cavity was a common feature in all 150 cases prior to treatment. After receiving group specific intervention these fibrous bands became supple initially and disappeared at last follow up in 44, 45 and 49 cases in group I, II and III respectively. Thus post treatment in 138 (92\%) cases the palpable fibrous bands disappeared completely $(\mathrm{p}<0.15)($ Table 4,5$)$.

\begin{tabular}{|c|c|c|c|c|}
\hline $\begin{array}{c}\text { Age in Years } \\
n=150\end{array}$ & Group I & Group II & Group III & Total \\
\hline $15-30$ & $10(20 \%)$ & $14(20 \%)$ & $11(22 \%)$ & $35(23.33 \%)$ \\
\hline $31-50$ & $16(32 \%)$ & $14(20 \%)$ & $10(20 \%)$ & $40(26.66 \%)$ \\
\hline $51-70$ & $24(48 \%)$ & $22(44 \%)$ & $29(58 \%)$ & $75(50 \%)$ \\
\hline $\begin{array}{c}\text { Group Wise Mean } \\
\text { Age } \pm \text { SD }\end{array}$ & $46.52 \pm 15.67$ & $43.86 \pm 16.53$ & $47.76 \pm 16.26$ & NA \\
\hline \multicolumn{5}{|c|}{ Table 2. Age Distribution } \\
\hline
\end{tabular}

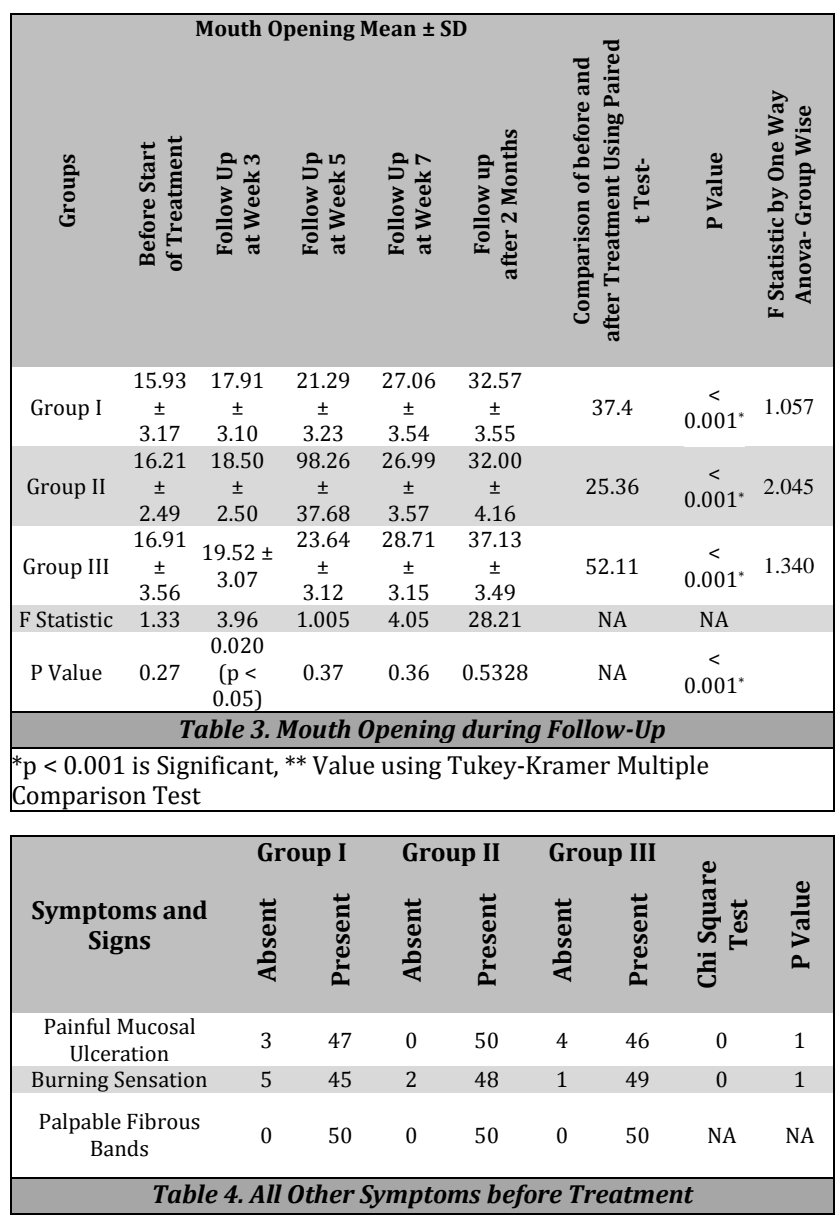

\begin{tabular}{|c|c|c|c|c|c|c|c|c|}
\hline \multirow[b]{2}{*}{$\begin{array}{c}\text { Symptoms and } \\
\text { Signs }\end{array}$} & \multicolumn{2}{|c|}{ Group I } & \multicolumn{2}{|c|}{ Group II } & \multicolumn{2}{|c|}{ Group III } & \multirow[b]{2}{*}{ 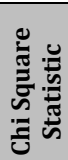 } & \multirow[b]{2}{*}{$\frac{\sqrt{2}}{\frac{\pi}{2}}$} \\
\hline & 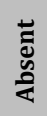 & $\begin{array}{l}\breve{\Xi} \\
\ddot{\Xi} \\
\vdots\end{array}$ & 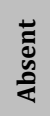 & 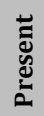 & $\begin{array}{l}\vec{\Xi} \\
\stackrel{0}{0} \\
\stackrel{0}{0}\end{array}$ & 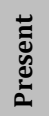 & & \\
\hline $\begin{array}{l}\text { Painful Mucosal } \\
\text { Ulceration }\end{array}$ & 46 & 4 & 49 & 1 & 48 & 2 & 5.4 & 0.16 \\
\hline Burning Sensation & 3 & 11 & 4 & 8 & 49 & 1 & 9.1 .9 & 0.01 \\
\hline Palpable Fibrous Bands & 44 & 6 & 45 & 5 & 49 & 1 & 3.8 & 0.15 \\
\hline
\end{tabular}

\section{DISCUSSION}

Lycopene is a potent antioxidant sourced from tomatoes. It exerts its anti-inflammatory action, by increasing the 
lymphocyte resistance to stress, inhibition of pivotal proinflammatory mediators like reduction of reactive oxygen species, the inhibition of synthesis and release of proinflammatory cytokines, changes in the expression of cyclooxygenase and lipoxygenase, modifications of eicosanoid synthesis and modulation of signal transduction pathways, including that of the inducible nitric oxide synthase. Also it prevents damage to cells by free radicals. Studies have shown that it reduces the susceptibility of lymphocyte DNA to oxidative damage, inactivates hydrogen peroxide $\left(\mathrm{H}_{2} \mathrm{O}_{2}\right)$ and nitrogen oxide (NO), and protects cells from NO-induced membrane damage and cell death. ${ }^{11}$ Lycopene inhibits hepatic fibrosis in rats and human fibroblast activity in vitro. Thus, it is beneficial in the management of OSMF.12

Intra-lesional injection of corticosteroid is being implemented as the first line therapy for patients with OSMF. The steroids act by opposing the action of soluble factors generated by sensitized lymphocytes after activation by specific antigens besides suppression of immunity and inflammatory reactions and thereby prevents fibrosis by decreasing fibroblastic proliferation and collagen deposition. ${ }^{13-16}$ The few studies on evaluation of the effectiveness of Lycopene in OSMF are available, whereas, a combination of lycopene with steroid and Lycopene alone as in this study has not been compared before.

In this study, the improvement in mean mouth opening at the end of the treatment in all 3 groups was $16.64 \pm 0.38$ (33.28 \%), $15.79 \pm 1.67$ (31.58\%) and $20.22 \pm 0.07 \mathrm{~mm}(40.44 \%)$ respectively and was significant. The study by Dipti et al, 2014 have found increase in the mouth opening by12 mm (37.62\%) in lycopene and $3.9 \mathrm{~mm} \mathrm{(13 \% )} \mathrm{with} \mathrm{intralesional} \mathrm{steroid}$ (betamethasone) groups. ${ }^{17}$ The reduction of burning sensation of oral cavity found in this study was in $75.5 \%$ of cases in group I (intralesional triamcinolone acetonide), $83.3 \%$ group II (Lycopene) and 97.9 \% group III (combination of both) which was not in accordance with above study by Dipti et al wherein it is $94.2 \%$ in Lycopene group and $70 \%$ in Steroid group. ${ }^{17}$ However, study by Dipti et al is concluded with 44 cases in two groups receiving single agent and not a combination. In a similar study conducted by Nidhi et al in 2014 , the improvement of mouth opening in group I (oral lycopene and local injection of steroid) was $59.5 \%(4.7 \mathrm{~cm})$ and group II (local injection of steroid) was $44.35 \%$ (3.5 cm). ${ }^{18}$ This study by Nidhi et al is concluded with 19 cases in each group and for a study period of 6 months. In this study the palpable fibrous bands disappeared in $88 \%, 90 \%$ and $98 \%$ of group I, II and III cases receiving intralesional triamcinolone acetonide, Lycopene and combination of both respectively. In this study group III (lycopene with intralesional triamcinolone acetonide) was better than group I (intralesional triamcinolone acetonide) and group II (Lycopene) for improving mouth opening and decreasing the burning sensation in mouth having OSMF.

\section{CONCLUSIONS}

OSMF a potentially precancerous condition which can be controlled by abstaining from indulgence of the predisposing factor and by medication for slowing down the pathology by using antioxidants and steroids as in 44,45 and 49 cases in group I, II and III respectively in this study. OSMF was equally affecting both males and females. The commonest age group affected was 51 to 69 years. Mouth opening in all groups improved significantly.

For effective treatment of OSMF associated with restricted mouth opening due to palpable fibrous bands, the combination of lycopene and triamcinolone acetonide (group III) must be employed. In OSMF associated predominantly with painful mucosal ulcerations, lycopene (group II) should be employed for healing and pain relief. For relief from burning sensation in oral cavity and throat a combination of lycopene and triamcinolone acetonide (group III) would be beneficial.

Overall, group III specific interventional drug-lycopene in combination with triamcinolone acetonide was more effective than triamcinolone acetonide and lycopene of group I and II used singly in improving the majority of symptoms and signs of OSMF.

Financial or Other Competing Interests: None.

\section{REFERENCES}

[1] Pindborg JJ, Sirsat SM. Oral submucous fibrosis. Oral Surg Oral Med Oral Pathol 1966;22(6):764-79.

[2] Gupta DS, Dolas R, Iqbal A. Treatment modalities in oral submucous fibrosis: how they stand today? Study of 600 cases. Indian J Oral Maxillofacial Surg 1992;7:43-7.

[3] Singh M, Krishanappa R, Bagewadi A, et al. Efficacy of oral lycopene in the treatment of oral leukoplakia. Oral Oncol 2004;40(6):591-6.

[4] Gopichand T. Otorhinolaryngology, submucous fibrosis of the palate. Karad: KIMS 1994:325-6.

[5] Kumar A, Bagewadi A, Keluskar V, et al. Efficacy of lycopenein the management of oral submucous fibrosis. Oral Surg Oral Med Oral Pathol Oral Radiol Endod 2007;103(2):207-13.

[6] Selvam NP, Dayanand AA. Lycopene in the management of oral submucous fibrosis. Asian Journal of Pharmaceutical and Clinical Research 2013;6(3):58-61.

[7] Maher R, Lee AJ, Warnakulasuriya KA, et al. Role of areca nut in the causation of oral submucous fibrosis: a casecontrol study in Pakistan. J Oral Pathol Med 1994;23(2):65-9.

[8] Heber D, Lu QY. Overview of mechanisms of action of lycopene. Exp Biol Med (Maywood) 2002;227(10):920-3.

[9] Palozza P, Parrone N, Catalano A, et al. Tomato lycopene and inflammatory cascade: basic interactions and clinical implications. Curr Med Chem 2010;17(23):2547-63.

[10] Passi D, Bhanot P, Kacker D, et al. Oral submucous fibrosis: newer proposed classification with critical updates in pathogenesis and management strategies. Natl J Maxillofac Surg 2017;8(2):89-94.

[11] Kakar PK, Puri RK, Venkatachalam VP. Oral submucous fibrosis--treatment with hyalase. J Laryngol Otol 1985;99(1):57-9.

[12] Kitade Y, Watanabe S, Masaki T, et al. Inhibition of liver fibrosis in LEC rats by a carotenoid, lycopene, or a herbal medicine, Sho-saiko-to. Hepatol Res 2002;22(3):196-205. 
[13] Borle RM, Nimonkar PV, Rajan R. Extended nasolabial flaps in the management of oral submucous fibrosis. Br J Oral Maxillofac Surg 2009;47(5):382-5.

[14] Naphade MV, Naphade UM. Major immunoglobulin status and lactate-dehydrogenaseis ozymeprofileinoralpremalignancy and malignancy. Dental Dialogue Official J IDA, MSB 2011;37:16-20.

[15] Tilakaratne WM, Ekanayaka RP, Herath M, et al. Intralesional corticosteroids as a treatment for restricted mouth opening in oral submucous fibrosis. Oral Surg Oral Med Oral Pathol Oral Radiol 2016;122(2):224-31.
[16] Singh M, Niranjan HS, Mehrotra R, et al. Efficacy of hydrocortisone acetate/hyaluronidase vs. triamcinoloneacetonide/hyaluronidase in the treatment of oral submucous fibrosis. Indian J Med Res 2010;131:665-9.

[17] Singh D, Shashikanth MC, Misra N, et al. Lycopene and intralesional betamethasone injections in the management of oral submucous fibrosis. J Indian Acad Oral Med Radiol 2014;26(3):264-8.

[18] Elizabeth N, Gurumani S, Bala GA, et al. A comparative study between management of oral submucous fibrosis. Journal of Evolution of Medical and Dental Sciences 2014;3(47):11344-8. 